\title{
THE RELATIONSHIP OF DIABETIC CONTROL WITH SERUM ALANINE AMINOTRANSFERASE LEVELS IN PATIENTS WITH NONALCOHOLIC FATTY LIVER DISEASE (NAFLD) AND TYPE 2 DIABETES MELLITUS (T2DM)
}

\author{
Saleem Iqbal, Hamza Ali khan, Muhammad Yousaf khan, Muhammad Darwesh lqbal, Badar Mahmud Shah, \\ Noor ul Iman \\ Department of Medicine Khyber Teaching Hospital, Peshawar - Pakistan
}

\begin{abstract}
Objectives: This study is aimed to find out the relationship of Diabetic control with serum Alanine aminotransferase in patients with Non Alcoholic Fatty Liver Disease and Type 2 Diabetes Mellitus.

Material and methods: This cross sectional descriptive study was conducted from August to October 2019 in general medical outpatient department of Khyber Teaching Hospital Peshawar, a tertiary care hospital in Khyber-Pakhtunkhwa, Pakistan. Patients with non-Alcohol Fatty Liver Disease and T2DM were categorized into two groups. Group A with $\mathrm{HbA1c}$ from 6.5-8\% and group $\mathrm{B}$ with $\mathrm{HbA} 1 \mathrm{c}$ of more than $8 \%$. Serum Alanine aminotransferase levels were correlated in these groups with the level of $\mathrm{HbA} 1 \mathrm{c}$. Data was collected through a specially designed proforma and was analyzed through statistical package for social sciences, SPSS version 23.

Results: Amongst 452 patients with T2DM, 289 were females and the rest were males. NAFLD was present in 197 patients. Amongst these 197 patients, Serum Alanine aminotransferase was raised in 17 (27.86\%) patients in Group A but was raised in $64(47.05 \%)$ patients in Group 2.

Conclusions: Diabetic control was positively correlated with serum Alanine aminotransferase level in our patients with Non Alcoholic Fatty Liver Disease and Type 2 Diabetes Mellitus.
\end{abstract}

Keywords: Type 2 Diabetes Mellitus, Non Alcoholic Fatty Liver Disease, Serum Alanine Aminotransferase.

This article may be cited as: Saleem I; Khan HA, Khan MY, Iqbal MD, Shah BM, Iman NU. The Relationship of Diabetic Control with Serum Alanine Aminotransferase Levels in patients with Nonalcoholic Fatty Liver Disease (NAFLD) And Type 2 Diabetes Mellitus (T2DM). J Med Sci 2021 January;29(1):10-12

\section{INTRODUCTION}

Type 2 diabetes mellitus (T2DM), is one of the most common metabolic disorder. Various genetic and acquired factors play their roles in the onset and manifestations of this disorder ${ }^{1,2,3,4}$. Insulin resistance is the major underlying factor and is a component of metabolic syndrome. The other components include abdominal obesity, hypertension, hypertriglyceridemia and low serum HDL cholesterol ${ }^{5,6}$. Non-Alcohol Fatty Liver Disease is now included as a component of metabolic syndrome. Patients with metabolic syndrome have 4 to 11 times higher risk of NAFLD as compared to people without metabolic syndrome. ${ }^{5,7}$. Non Alcoholic Fatty Liver Disease (NAFLD) re-

\section{Correspondence}

\section{Dr. Hamza Ali Khan}

Department of Medicine Khyber Teaching Hospital,

Peshawar - Pakistan.

Email: hamzaalikhan48@gmail.com

Cell: +92-333-9333841

Date received: $21-04-2020$

Date revised: $\quad 07-08-2020$

Date accepted: 10-01-2021 fers to the accumulation of fat, mainly triglycerides in hepatocytes leading to increase in liver weight of up to $5 \%$, provided patient is taking less than 20 grams of alcohol/ day (i.e. approximately 2 standard drinks), and patients do not have viral hepatitis ${ }^{8}$. Primary NAFLD results from insulin resistance. More than $40 \%$ of patients with NAFLD have obesity, while more than $20 \%$ have T2DM and hypertriglyceridemia and may have other features of metabolic syndrome ${ }^{9,10}$.

As one of the common cause of raised serum Alanine aminotransferase is NAFLD, so we want to assess the relationship of diabetic control with serum alanine aminotransferase in patient having both Non Alcoholic Fatty Liver Disease and T2DM ${ }^{1,9}$.

\section{MATERIAL AND METHODS}

This cross sectional descriptive study was conducted in general medical outpatient department of Khyber Teaching Hospital Peshawar, from August to October2019, after approval from the Committee for Ethical Review of Research involving Human Subjects of Khyber 
The Relationship Of Diabetic Control With Serum Alanine Aminotransferase Levels In Patients With Nonalcoholic Fatty...

Teaching Hospital. All patients, $>14$ years of age, having Type 2 Diabetes Mellitus for more than two years and Nonalcoholic Fatty liver disease, who agreed to be included in the research, were included in the study. Patients below age 14, patients having Type 1 Diabetes Mellitus, patients having comorbid conditions especially those affecting $\mathrm{HbA1c}$, were excluded from the study. Diabetes mellitus was confirmed by doing fasting plasma glucose (equal to or more then $126 \mathrm{mg} \%$ ) or random plasma glucose (equal to or more the $200 \mathrm{mg} \%$ ) or $\mathrm{HbA} 1 \mathrm{c}$ more than $6.5 \%$. The upper limit of normal for Serum Alanine aminotransferase was 30iu/L for men and $19 \mathrm{iu} / \mathrm{L}$ for women ${ }^{1}$. Though biopsy is the gold standard for confirmation of NAFLD but liver biopsy being an invasive procedure is not recommended in asymptomatic individuals ${ }^{5}$. Further as ultra-sonogram has the sensitivity of $80 \%$ and specificity of $98 \%$ so ultra-sonogram was our investigation of choice ${ }^{12}$. In order to avoid bias due to individuals ultra sound was performed by a qualified radiologist ${ }^{5,11,12}$. Data thus collected according to a preformed proforma, was analyzed through statistical package for social sciences (SPSS version 23), where chi-square test was applied to find out the relationship between the two groups and p-value of 0.05 or less was considered significant for correlation.

\section{RESULTS}

Out 1500 patients examined in out patients, only $452(30.13 \%)$ patients had type 2 Diabetes Mellitus, $289(63.93 \%)$ were females and the males were only $163(36.06 \%)$. The mean age of patients with T2DM was 53.87 years, amongst the 452 patients with T2DM, Non Alcoholic Fatty Liver Disease was present in only 197(43.58\%) patients.

\section{DISCUSSION}

Out of 1500 patients examined, 452 patients had T2DM, which accounts for $30.13 \%$ of the total patients, a figure which is significantly higher than another figure of $11.7 \%$, published recently ${ }^{13}$. Out of these 452 patients 197 (43.58\%) had NAFLD. Depending upon the populations

Table 1: Demographics of the Patients with T2DM

\begin{tabular}{|c|c|c|c|}
\hline & $\begin{array}{l}\text { Patient without } \\
\text { T2DM }\end{array}$ & $\begin{array}{l}\text { Patient with } \\
\text { T2DM }\end{array}$ & P Value \\
\hline \multicolumn{4}{|c|}{$\begin{array}{l}\text { Frequency of the patients presenting to Medical OPD with } \\
\text { T2DM }\end{array}$} \\
\hline & 1500 & 452 & \\
\hline \multicolumn{4}{|c|}{$\begin{array}{l}\text { Age wise distribution of the patient presenting to the Medical } \\
\text { OPD }\end{array}$} \\
\hline Mean + S.D & $47.18+16.42$ & $53.87+11.41$ & 0.000 \\
\hline \multicolumn{4}{|c|}{$\begin{array}{l}\text { Gender wise distribution of the patient presenting to the } \\
\text { Medical OPD }\end{array}$} \\
\hline Male & 507 & 163 & \multirow[t]{3}{*}{0.47} \\
\hline Female & 993 & 289 & \\
\hline Total $(n=1952)$ & 1500 & 452 & \\
\hline
\end{tabular}

Table 2: Presence of NAFLD in T2DM Patients

\begin{tabular}{|c|c|c|c|}
\hline $\begin{array}{c}\text { Blood Sugar } \\
\text { Levels }\end{array}$ & Present & Absent & $\begin{array}{l}\text { Pear- } \\
\text { son's R }\end{array}$ \\
\hline Group A $(n=153)$ & 61 (39.86\%) & $92(60.13 \%)$ & \multirow[t]{3}{*}{0.64} \\
\hline Group B $(n=299)$ & 136 (45.48\%) & $173(54.51 \%)$ & \\
\hline Total $(n=452)$ & 197 (43.58\%) & 255 (56.41\%) & \\
\hline
\end{tabular}

Table 3: Correlation of Diabetic status with the serum ALT in patients with NAFLD \& T2DM

\begin{tabular}{|c|c|c|c|}
\hline $\begin{array}{l}\text { Blood Sugar } \\
\text { Levels }\end{array}$ & $\begin{array}{l}\text { Within Nor- } \\
\text { mal Limits }\end{array}$ & Elevated & $\begin{array}{c}\text { Pearson's } \\
\text { R }\end{array}$ \\
\hline Group A $(n=61)$ & $44(72.13 \%)$ & $17(27.86 \%)$ & \multirow[t]{3}{*}{0.011} \\
\hline Group B $(n=136)$ & 72 (52.94\%) & $64(47.05 \%)$ & \\
\hline Total $(n=197)$ & $116(58.88 \%)$ & $81(41.11 \%)$ & \\
\hline
\end{tabular}

studied, 21-72\% patients with Type 2 Diabetes mellitus have been reported to have NAFLD ${ }^{14}$. NAFLD was present in 61 (39.86\%) in group $A$ and in 136 (45.48\%) patients in Group B, i.e., slightly higher in patients with $\mathrm{HbA} 1 \mathrm{c}$ of more than $8 \%$ as compared to group $A$ with $\mathrm{HbA} 1 \mathrm{c}$ of between $6.5-8 \%$. Over all, 81 (41.11\%) patients suffering from T2DM had elevated serum alanine aminotransferase level. This figure is significantly lower than $61.2 \%$ published by Shiful Islam from Bangladesh ${ }^{15}$. The probable reason being that our population looks to be different from people of Bangladesh in many respects. But exactly a similar figure of $41.05 \%$ has been reported by a local study about two years ago from same area ${ }^{16}$. On further observations, we found that serum alanine aminotransferase was elevated in only $17(27.86 \%)$ of patients in Group A, in which the $\mathrm{HbA} 1 \mathrm{c}$ was between $6.5-8 \%$, but serum alanine aminotransferase was raised in 64 (47.05\%) in patients of Group B with $\mathrm{HbA1c}$ of more than $8 \%$. The figure in Group B is almost double as compared to the figure of Group A. This means that in patients suffering from T2DM and NAFLD, worsening of diabetic status is associated with elevation of serum alanine aminotransferase level. In other words serum level of alanine aminotransferase in patients suffering from both T2DM and NAFLD is positively correlated with blood glucose level. Serum alanine aminotransferase is considered as the surrogate marker of NAFLD. Up to $30 \%$ of patients with NAFLD have the evidence of metabolic syndrome and insulin resistance i.e. T2DM ${ }^{1}$. A number of studies have been published in which the Serum level of Alanine Aminotransferase has been correlated in patients suffering from NAFLD and T2DM with insulin resistance. The insulin resistance is the major cause of T2DM. Tough some studies have shown that serum level of alanine aminotransferase may be normal in patients suffering from NAFLD and T2DM, but a number of studies have confirmed that serum level of aminotransferase gets elevated with worsening of glycemic status and higher serum level of alanine aminotransferase is associated with insulin resistance for example JangSuk Yoo et al and Rui Wang $^{17,18,19}$. 
The Relationship Of Diabetic Control With Serum Alanine Aminotransferase Levels In Patients With Nonalcoholic Fatty...

\section{CONCLUSION}

Diabetic control was positively correlated with serum Alanine aminotransferase level in our patients with Non Alcoholic Fatty Liver Disease and Type 2 Diabetes Mellitus.

\section{REFERENCES}

1. Bayard M., Holt J, Boroughs E. Nonalcoholic fatty liver disease. American Family Physician 2006;73:1961-68.

2. Iran JP Waamethee G, Walker MK, Thomson AG, Whincupph. Prospective study of risk factors for development of noninsulin dependent diabetes in middle aged British men: Br Med J 1995; 310:560-64.

3. Leiden HAV, Jacqueline M. Annetted, Nijpels G, Heiner J. Blood pressure lipids and obesity are associated with retinopathy. Diabetes Care 2002; 25: 1320-5.

4. Anne M, Conaway WMR, Crowther JQ, Hazen KY, Nadlerjl, Oneida B, et al. Translating lifestyle intervention to practice in obese patients with type 2 diabetes. Diabetes Care 2004; 27: 1570-6.

5. Friedman IS. Nonalcoholic fatty liver disease, liver, biliary tract and pancreatic disorders. Maxine A Papadakis, Stephen J Mcphee, Michael W Rabow. Current medical diagnosis \& treatment, fifty sixth edition, New York, Mc Grawhill, 2020; 59:715-7.

6. Bishore TM, Granger CB, Jackson KP, Patel MR. Coronary heart disease. Maxine A Papadakis, Stephen J Mcphee, Michael W Rabow. Current medical diagnosis \& treatment, fifty sixth edition, New York, Mc Grawhill, 2020; 59:369-97.

7. Rinella ME. Nonalcoholic Fatty Liver Disease, a systemic review. JAMA. 2015 Jun 9;313(22):2263-73.

8. Lawrence S Friedman. Nonalcoholic Fatty Liver Disease, Liver, Biliary Tract and Pancreatic Disorders. Maxine A Papadakis, Stephen J Mcphee, Michael W Rabow. Current Medical Diagnosis \& Treatment, Fifty ninth edition, New York, Mc Graw Hill, 2020; 59:693-5.

9. Kang H, Joll K, Jason T, Laura FW, Hari S. Metabolic syndrome is associated with greater histological severity, higher carbohydrate and lower fat diet in patients with non-alcoholic fatty liver disease. Am J Gastroenterol 2006; 101:2247-53.

10. Mcavoy NC, Ferguson JW, Campbell IW, Hayes PC. Non-alcoholic fatty liver disease: natural history, pathogenesis and treatment: $\mathrm{Br} \mathrm{J}$ Diabetes Vasc Dis 2006; 6:251-60.

11. Rector RA, John PT, Yangzhong W, Ibdah JA. Non-alcoholic fatty liver disease and metabolic syndrome: an update. World J Gastroenterol 2008 Jan 14;14(2):185-92.

12. Qari FA, Ai Ghamdi A. Fatty liver in overweight and obese patients in Western part of Saudi Arabia: a study of sonological prevalence. Pak J Med Sci 2005;21:143-7.

13. Meo SA, Zia I, Bukhari IA, Arain SA. Type 2 diabetes mellitus in Pakistan: Current prevalence and future forecast.
J Pak Med Assoc.2016;66(12):1637-42.

14. Angulo P. Gl Epidemiology: Non Alcoholic Fatty Liver Disease. Aliment Pharmacol Ther 2007; 25(8):883-9.

15. Islam $\mathrm{S}$, Rahman $\mathrm{S}$, Haque $\mathrm{T}$, Summon $\mathrm{AH}$, Ahmed AM, Ali N., Prevalence of Elevated Liver Enzymes and Its Association With Type 2 Diabetes: A Cross-Sectional Study in Bangladeshi Adults. Endo Diabetes Metab. 2020Feb12;13(2):e00116

16. Iqbal S, Khan S, Iqbal MD, Iman NU. Frequency of Non-Alcohol Fatty Liver Disease in General Medical Out patients. J Med Sci. July 2018;26(3):202-6.

17. Paola Portillo-Sanchez, Fernando Bril, Maryann et al. Higher Prevalence of Nonalcoholic Fatty Liver Disease in Patients with Type 2 Diabetes Mellitus and normal plasma Aminotransferase Level. Journ of Clin Endocrin \& Metab 2005 June; 100(6):2231-8

18. JangSuk Yoo, Seon Yeong Lee, KyuNam Kim, et al. Relationship between insulin resistance and serum alanine aminotransferases a surrogate of NAFLD (Nonalcoholic Fatty Liver Disease) in obese Korean Children. Diabetes Res Clin Prac 2008 Sep;81(3):321-6.

19. Rui Wang, Qiang Lu, Ji Feng et al. Coexistance of Non-Alcoholic Fatty Liver Disease with elevated Alanine Aminotransferase Is associated with Insulin Resistance in Young Han Males. Endocrine 2012 Feb; 41(1):70-5.

CONFLICT OF INTEREST: Authors declare no conflict of interest

GRANT SUPPORT AND FINANCIAL DISCLOSURE: NIL

\section{AUTHOR'S CONTRIBUTION}

Following authors have made substantial contributions to the manuscript as under

Iqbal S: $\quad$ Concept, study design, discussion, manuscript writing, facilitation of the reagent and materials, critical review

Khan HA: Facilitation of the reagent and materials, critical review, interpretation.

Khan MY: $\quad$ Analysis, interpretation, manuscript writing, study conduction.

Iqbal MD: Analysis, interpretation, manuscript writing, study conduction

Shah BM: Critical review, study conduction.

Iman NU: Over all supervision

Authors agree to be accountable for all aspects of the work in ensuring that questions related to the accuracy or integrity of any part of the work are appropriately investigated and resolved. 